\title{
Artificial intelligence and patents: DABUS and methods for attracting enhanced attention to inventors
}

For it holds it like glue Holds the lid to the dish, while it lies in the middle:

Which is easiest to do, Un-dish-cover the fish, or dishcover the riddle?

(Lewis Carroll, Through the Looking-Glass, and What Alice Found There, 1872)

\section{INTRODUCTION}

Over thirty years ago, in a text that has remained persistently influential on the nature of scientific discovery, the authors remarked on the innovation and authorship of the formulation of a problem, and the authorship of subsequent innovations upon that discovery. ${ }^{1}$ On the provenance of innovation, their words remain striking:

It is clear that credit for discovery is awarded to a scientist who finds an important law, whether or not he or she was the first to formulate the problem of looking for a law in the phenomena under consideration. To assert this is not to claim that problem finding and problem formulation may not also be creative activities, important for discovery. There is no reason why we must exclude the one species of creativity in order to recognize the other. ${ }^{2}$

The authorship and provenance of invention through the use of artificial intelligence (AI) continues to preoccupy legal, social and political discourse. At the time of going to press, the UK Intellectual Property Office (IPO) had launched its consultation into AI and intellectual property, which includes as a specific area of consultation, 'Patent protection for AI-devised inventions. Should we protect them, and if so, how should they be protected?' ${ }^{3}$ And over the past three years, and with recently 'enhanced attention' through a series of judicial appeals, two patent applications have been giving cause to test the limits and overstep the bounds of patent law; not only in terms of the concept of the inventor, but also its import, in every sense of the word. The 'author' of the problem, as it were, the circumstances for this embroilment and wrangling, is a machine named DABUS.

\section{WHAT'S IN A NAME?}

Stephen Thaler, the applicant, is a physicist and the President and CEO of Imagination Engines, an entity built around a series of inventions principally concerning artificial

1. P Langley et al., Scientific Discovery: Computational Explorations of the Creative Process (The MIT Press, Cambridge, MA 1987).

2. Ibid 26.

3. UK Intellectual Property Office (IPO), Artificial Intelligence and Intellectual Property: Copyright and Patents (29 October 2021). 
neural networks and related technologies. Several of these inventions refer to 'autonomous bootstrapping', including the US patent for a 'Device and Method for the Autonomous Bootstrapping of Unified Sentience', ${ }^{4}$ or DABUS. DABUS is the protagonist in this story, the object in this dispute, the sting in the invention tale. ${ }^{5}$

Thaler is asking patent authorities to recognize a machine, DABUS, as an inventor or risk the consequences of an invention without an author, ${ }^{6}$ and it is the recent Court of Appeal decision ${ }^{7}$ on the UK applications that preoccupies the present discussion. The inventions in question are a 'Food container' and 'Devices and methods for attracting enhanced attention' (which relates to the use of pulse trains to LEDs or lamps). Each of the two patent applications cites as the inventor, 'DABUS, The invention was autonomously generated by an artificial intelligence'. ${ }^{8}$ The campaign, so to speak, is known as the Artificial Inventor Project. ${ }^{9}$

The claim for AI-inventorship has been declined by the US District Court ${ }^{10}$ and the European Patent Office. ${ }^{11}$ However, this position on the matter is not necessarily ubiquitous. There was significant international attention when, in late July, two contrary perspectives were pronounced. First, the South African Patent Office published the granted patent ${ }^{12}$ without challenging the claim to inventorship. And second, the Federal Court of Australia ${ }^{13}$ set aside the determination of the Deputy Commissioner of Patents and allowed for AI inventorship. The Deputy Commissioner had previously determined that the application was not compliant and therefore had lapsed. ${ }^{14}$ However, IP Australia is currently appealing the decision

4. Stephen L Thaler, Device and Method for the Autonomous Bootstrapping of Unified Sentience. US Patent 10.423.875. September 24, 2019.

5. Together, these various inventions appear to be the basis for the 'Creativity Machine', a registered trade mark for 'Artificial neural networks in the form of computer software and code used for autonomous artificial intelligence data processing and generation', 'Installation of artificial neural networks' and 'consulting in the field of artificial neural network technology', amongst other goods and services. The mark, 'Creativity Machine', is registered in Classes 9, 37 (Installation of artificial neural networks) and 42 (Development and design of artificial neural networks and consulting in the field of artificial neural network technology): US TM Reg No 2304506, registered 28 December 1999. The mark 'Imagination Engines' is also registered in Classes 9, 37 and 42, US TM Reg No 2298457, registered 7 December 1999. See further SL Thaler, 'Vast Topological Learning and Sentient AGI' (2021) 8(1) Journal of Artificial Intelligence and Consciousness 81-111. See further $<$ https://artificialinventor.com/frequentlyasked-questions/>.

6. <https://artificialinventor.com/dabus/>.

7. Thaler v Comptroller General of Patents, Trade Marks and Designs [2021] EWCA Civ 1374.

8. WO2020079499, priority date, 17 October 2018. As mentioned earlier, in the national phase these have been rationalized as two separate applications: 'Food container' and 'Devices and methods for attracting enhanced attention'.

9. <https://artificialinventor.com>.

10. Thaler v Hirshfeld (E.D. Va, 2 September 2021) (Case 1:20-cv-00903-LMB-TCB).

11. For the identification of the inventor, the current EPO applications have entered 'The designation of the inventor has not yet been filed' and include the remarks 'The designation of inventor does not meet the requirements laid down in Article 81 and Rule 19 EPC'. The EPO decision is currently under appeal to the Legal Board of Appeal: J 8/20; J 9/20.

12. Companies and Intellectual Property Commission, Patent Journal, Part II, 28 July 2021, p. 255.

13. Thaler $v$ Commissioner of Patents [2021] FCA 879.

14. The identification of an AI machine as an inventor was determined to be inconsistent with $\mathrm{s}$ 15(1) of the Patents Act (Cth), and therefore the application was deemed to have lapsed as it did not comply with the direction under regulation 3.2C(4): [2021] APO 5 (9 February 2021). 
and, in a press release a month after the Federal Court decision, the Commissioner stated that the issue is one of public importance, while at the same time emphasizing that, 'The decision to appeal does not represent a policy position by the Australian Government on whether AI should or could ever be considered an inventor on a patent application'. ${ }^{15}$

Despite, or perhaps because of, the refusal to accept the machine as an inventor in major patent jurisdictions like the US, UK and EPO, DABUS has become the personality of the AI inventor debate itself. Is DABUS to become the inventor of AI rights? Is DABUS, itself devised, to become the actual deviser of the AI inventor?

\section{WHAT IS IT LIKE TO BE AN INVENTOR?}

The concept of sentience is not only an element of the name DABUS itself, but also a central concern of the Artificial Inventor Project. Thaler explains the concept of Vast Topological Learning (VTL) ${ }^{16}$ as the basis for Sentient Artificial General Intelligence (SAGI): 'VTL comes even closer to modelling cognition, consciousness, and sentience since it allows the generation of much more complex concepts. ${ }^{17}$ As for DABUS the inventor, Thaler asserts: 'VTL, and its first implementation in DABUS, demonstrates that it is much more than an AI tool for invention and discovery, being an autonomous synthetic intelligence that absorbs and contemplates its world, its revelations guided, appreciated, and selectively reinforced by its subjective feelings (i.e., sentience). ${ }^{18}$ But in this assertion, the advocacy of the Artificial Inventor Project is not for personhood, but for inventorship: 'We are not advocating for an AI to own its own patents. We are advocating for the AI's owner to own patents on any AI-generated inventions. AI does not have legal personality and cannot own property. ${ }^{19}$

This distinction between personhood and inventorship is important for reasons far more interesting than advocacy strategy. And the importance of this distinction is perhaps too easily overlooked in the legal discourse surrounding artificial intelligence (AI) and the rhetoric of personhood. Indeed, it is perhaps all too easily overlooked in nonhuman animal advocacy as well. ${ }^{20}$ Arguably we are happy to imagine and accept personhood without sentience, as in the convenience of the legal fiction of personhood for corporations, or the harmonization of customary and statutory law in the case of personhood for rivers. ${ }^{21}$ That said, it could be argued that a systemic approach to personhood is what is imagined for the river, and so the sentience of a living

15. IP Australia, Commissioner to appeal court decision allowing artificial intelligence to be an inventor, Press Release, 30 August 2021.

16. According to Thaler, 'Vast topological learning involves multiple artificial neural nets ... that autonomously form chains ... to encode more complex concepts', and that '[w]ithin this encoding scheme, complex concepts are assembled from simpler ones, oftentimes bonding with other chains representing the connecting logic between them or the overall notion's anticipated effects': Thaler (n 5) 83.

17. Thaler (n 5) 102.

18. Ibid 108 .

19. <https://artificialinventor.com/frequently-asked-questions/> (emphasis in original).

20. J Gibson, 'Animals and Property: A Person Possessed', in N Graham et al. (eds), Routledge Handbook of Property, Law and Society (Routledge, London forthcoming).

21. For example, Te Awa Tupua (Whanganui River Claims Settlement) Act 2017 (NZ). See further the discussion in Erin O'Donnell, 'Rivers as Living Beings: Rights in Law, but No Rights to Water?' (2020) 29(4) Griffith Law Review 643-68. 
ecosystem is what is at stake. But is that the argument for corporations? A room full of sentient beings? That would seem to be a stretch if not a strain. What would it mean in terms of welfare, authorship and rights - if sentience were to be decoupled from personhood? What if rights were to be understood through artefacts, as a trace of creativity, invention, performance and, indeed, sentience? ${ }^{22}$

To emphasize personhood or legal personality as an absolute is arguably to be defeated by the inevitability of ownership and property that is potentially insisted by such status. And if invention is shown to be nothing more than in name, the alienation of the object from its creator seems all but complete within the reckonings of the patent system. But what if the emphasis is instead on creativity, on authorship, on invention? In other words, rather than relying on a shifting threshold of sentience for a consideration of $\mathrm{AI}$ invention and authorship, it is the object of invention that makes the inventor. We should heed the words of Birss LJ, that the DABUS litigation 'is an object lesson in the risks of advocacy being distracted by glamour'. ${ }^{23}$ But we should do so with a slight inflection; this object lesson in the present disputes is almost certainly at risk of being distracted by the glamour that attaches to the discourse surrounding AI. This is not a discussion of sentience and autonomous robots and how they feel about and make inventions. This is a question of the way we make inventors.

What is it like to be an inventor? The answer appears to come not from the inventor, as such, but from 'any other person'.

\section{THE COURT OF APPEAL'S OBJECT LESSON}

It may seem, in the decision of the Court of Appeal of England and Wales, that the reliance on the text of the statute is the end of the matter, but the rich interlocutory in the oral proceedings is a resource in and of itself. This decision is somewhat outstanding for the questions that it asks, rather than the bounds that it acknowledged. As for the decision itself, the court declined to recognize DABUS as an inventor, based on the drafting of the Patents Act 1977 itself. The Act provides that the inventor is 'the actual deviser of the invention', ${ }^{24}$ and that in applying for a patent the applicant must identify 'the person or persons he believes to be the inventor or inventors'. ${ }^{25}$ Not in dispute were the court's starting assumptions - that there is an invention and that Thaler was correct in his belief that the inventor is DABUS. However, pursuant to section 13, the application is thus deemed to be withdrawn on the basis of the refusal to name an inventor; that is, the refusal to name a person. Nevertheless, the court went on to consider the nature of the relationship between DABUS and Dr Thaler, and specifically, the nature of Dr Thaler's entitlement, if any, to own the invention.

Dr Thaler was not claiming entitlement on the basis that he was the inventor, ${ }^{26}$ nor as a successor in title ${ }^{27}$ - the latter being almost a kind of 'legal impossibility' in terms

22. This argument is developed further in J Gibson, Wanted, More than Human Intellectual Property (Routledge, London forthcoming).

23. Thaler v Comptroller General of Patents, Trade Marks and Designs [2021] EWCA Civ 1374: Birss LJ [1].

24. Patents Act 1977, s 7(3).

25. Patents Act 1977, s 13(2)(a). For a full consideration of the interpretation of the inventor as person, see Thaler $v$ Comptroller General of Patents, Trade Marks and Designs [2021] EWCA Civ 1374: Arnold LJ [113-123].

26. Patents Act 1977, s 7(2)(a).

27. Patents Act 1977, s 7(2)(c). 
of the culpability that may attach to ownership, since DABUS has no legal personality and therefore cannot be the owner of the patent, nor can it transact that intellectual property. Instead, Dr Thaler's claim was that, as the owner of DABUS, he was entitled to apply for the patent pursuant to section $7(2)(b)$, which sets out circumstances where the relationship between the inventor and 'any person or persons' means that the person or persons are 'entitled to the whole of the property in it'. ${ }^{28}$ The circumstances, in the present case, were argued to be found in the common law doctrine of accession; that is, that the owner of DABUS would be entitled to anything DABUS produced. Accession is thus the doctrine by which the grapes are the property of the owner of the vines, the calf is the property of the owner of the cow. ${ }^{29}$

Birss LJ offered the precedent of St Columba's copying of Abbott Fenian's Psalter, where King Diarmait ${ }^{30}$ gave judgment for the Abbott: 'to every cow her calf, and accordingly to every book its copy'. ${ }^{31}$ Arnold LJ argued that 'the analogy is at best an imperfect one, because ... the reason why Abbott Fenian would have had copyright in his Psalter was because he was the author of the literary work, whether or not he owned the parchment upon which it was inscribed'. ${ }^{32}$ However, what if the relevant relationship between Thaler and DABUS is not that of owner and object, but that of inventor and invention? Might this address or merely compound the legal complexity? Nevertheless, Thaler's argument did not succeed and the court found that he was not entitled to apply for patents on anything that DABUS might invent. ${ }^{33}$

\section{WHAT IS IT LIKE TO OWN AN INVENTOR?}

The wider reactions to the denial of inventorship in the Court of Appeal decision, and indeed in other jurisdictions, appear to share a common thread of provenance and the accountability perceived to be secured by that naming. Many of these current arguments focus upon traditional approaches to intellectual property through incentives. For the most part these arguments are concerned with the industries that are deploying $\mathrm{AI}$ in the service of innovation, and their potential vulnerability if AI cannot be named as inventor for an invention in which the human involvement is not clearly demonstrated. ${ }^{34}$ However, the emphasis on the AI as the sole inventor may present an even greater risk. Ryan Abbott, in representing Thaler, has rejected publicly the notion of adding a human name as joint inventor: "we will not be doing that because there is no person, at least according to traditional criteria, who we believe qualifies as an

28. Patents Act 1977, s 7(2)(b).

29. William Blackstone, Commentaries on the Laws of England (Clarendon Press, 1765-1770): Book 2, Chapter 26.

30. King of Tara, High King of Ireland. Died c 565 CE.

31. As to the possibly mythological nature of this account, see Jeremy Phillips, 'St Columba the Copyright Infringer' [1985] 12 European Intellectual Property Review 350-53.

32. Thaler v Comptroller General of Patents, Trade Marks and Designs [2021] EWCA Civ 1374: Arnold LJ [134].

33. Thaler v Comptroller General of Patents, Trade Marks and Designs [2021] EWCA Civ 1374, Arnold LJ [137]: 'In my judgment there is no rule of law that a new intangible produced by existing tangible property is the property of the owner of the tangible property.'

34. Stephanie Skaff et al. ask, 'Are innovators who increasingly rely on AI to analyze data and generate solutions atop a slippery slope?' See S Skaff et al., 'Artificial Intelligence Can't Patent Inventions: So What?', IP Watchdog, 13 July $2020<$ https://www.ipwatchdog.com/2020/07/13/ artificial-intelligence-cant-patent-inventions/id $=123226 />$. 
inventor' ${ }^{35}$ What does it mean then, and how might this entitlement be established, if a person may own an inventor?

Indeed, the question of the rights of owners of creative agents to the rights in the invention remains outstanding. But this question of entitlement is important, particularly in the context of the wider considerations of sentience. If the owner of a nonhuman creative agent becomes the owner of the intellectual property (if not the inventor), this might suggest a potential bound servitude of nonhuman creators within this dynamic. Arguably, nonhuman animal creators are already subject to this subjugation. For example, if an endangered Celebes crested macaque (a monkey) takes a photograph, ${ }^{36}$ and the US Copyright Office (for example) refuses to register a work by a monkey (for example), ${ }^{37}$ can the owner of the camera be the author? ${ }^{38}$ The overwhelming consensus is that, notwithstanding whether a monkey is or is not an author, the owner of the camera does not own the photograph. And because a photograph by a monkey cannot qualify as a work of authorship, then nobody owns the photograph. ${ }^{39}$ In the UK, lending someone a camera to take a photograph does not make the owner of the camera the author of the work. ${ }^{40}$ Or is the photograph (and much of the world of wildlife photography) in the public domain? However, the author of a computer program that generates works is taken to be the author of those computer-generated works. ${ }^{41}$ Are these two approaches reconcilable? Is it possible that the provenance for the invention may be found not in Thaler's ownership, but in his invention of DABUS? His authorship of the author?

\section{THE WELFARE QUESTION}

The Chartered Institute of Patent Attorneys (CIPA) approaches the issue from the perspective of largely economic incentives for research as perceived to be provided by patents.

35. Ryan Abbott, quoted in K Quach, 'I'm Doing This to Stop Humans Ripping Off Brilliant Ideas by Computers and Aliens, Says Guy Unsuccessfully Filing Patents "Invented" by his AI', The Register, 29 April $2020<$ https://www.theregister.com/2020/04/29/ai_patent_denied/>. See further Thaler v Comptroller-General of Patents, Designs and Trade Mark [2020] EWHC 2412 (Pat), [49(3)(d)]; and Thaler v Comptroller General of Patents, Trade Marks and Designs [2021] EWCA Civ 1374, [23].

36. Naruto the Macaque's self-portrait, uploaded to Wikimedia Commons $<$ https://commons. wikimedia.org/wiki/File:Macaca_nigra_self-portrait.jpg\#filehistory>.

37. United States Copyright Office, Compendium of US Copyright Office Practices, Chapter 300: see 313.2 Works That Lack Human Authorship: 'To qualify as a work of "authorship" a work must be created by a human being ... The US Copyright Office will not register works produced by nature, animals, or plants.' But while the objects do not qualify as works of authorship for the purposes of copyright, are the creators not authors?

38. Naruto v Slater, 999 F.3d 418 (9th Cir. 2018).

39. William F Patry, Patry on Copyright (West, 2021 Update), §21:7.

40. Prior to the UK Copyright, Designs and Patents Act 1988, the law was somewhat different. For instance, under the UK Copyright Act 1956, s 48(1), photograph is defined to mean 'any product of photography or of any process akin to photography ... and "author", in relation to a photograph, means the person who, at the time when the photograph is taken, is the owner of the material on which it is taken'. Thus, if a company owns the materials (the film), a company could be the author; in other words, an owner as author and indeed a legal person as author, or a nonhuman author. However, since 1988, the photographer is the author: $\mathrm{s} 9$. The transitional provision regarding authorship for works existing at the time of the coming into force of the 1988 is found in Sch 1, para 10.

41. Copyright, Designs and Patents Act 1988, s 9(3). 
In a Discussion Paper, the CIPA notes the potential uncertainty of patents for inventions with no inventor, the consequent negative impact in AI-supported research and development, identifying the recognition of AI inventors and a clarification of ownership as a way to resolve this uncertainty. ${ }^{42}$ Notably, the CIPA suggests the potential need for an integrated approach to the responsibility of AI across a wider landscape of legal and social accountability, beyond the invention narrative. ${ }^{43}$

However, the dismal science of economics is no match for the sparkling glamour of AI. Advocates for recognizing creative agency in AI also frame the question of authorship and inventorship as one of fairness and welfare. It is in this context that the relationship between trust and intellectual property becomes more emphatic, and the notion of intellectual property as a welfare tool becomes more apparent. The wider discussion surrounding DABUS and the claims to inventorship is indeed framed by questions of welfare, not only of the public and its access to innovation, but also of the machines themselves, whatever that might mean. Thaler has argued that: 'As AI begins to crank out progressively more inventions, humans will watch and be tempted to file patents that they really didn't conceive. Of course there would be consequences for such dishonesty.' 44

Those consequences are not necessarily immediately clear. However, they do not appear to be about narratives of standing and retribution; rather, they are consequences in relation to the innovative system itself. In the operation of the patent system, it appears that any person can apply for a patent, and any person can be named as inventor, and it is certainly not within the purview of patent offices around the world to enter into a factual inquiry as to the veracity of the names on the document. Arguably, the system 'corrects' itself in that the actual inventor may subsequently challenge the document and indeed correct the record. However, if AI is not a person and cannot challenge, then such a document may stand, and it is the patent that makes the inventor. This is the object lesson of the patent system, the making of inventors through its objects, the making of creators through artefacts.

It would seem that part of the motivation for the Artificial Inventor Project, and this certainly informed oral submissions during the hearing, is to address this question of provenance through a greater affiliative relationship between inventor and invention. In other words, intellectual property's value as a welfare tool, both in terms of societal benefit and individual creators, is in the quality of attribution. Incentives are merely a construction of convenience, after the fact. ${ }^{45}$

Thus, Thaler's implication that AI might be exploited through the 'dishonesty' of human applicants becomes more clearly an assertion about trust and authorship as related to the relationship with the user, the consumer, the public. Patents are about not only the objects of invention, but also the use of those objects, and trust through the provenance of invention. That provenance is not only in the history of objects (through novelty and prior art) but also in the naming of authors.

42. The Chartered Institute of Patent Attorneys (CIPA), Patenting Inventions Created Using an AI System: A CIPA Discussion Paper (June 2020).

43. In this context, the current consultation by the Department for Digital, Culture Media \& Sport (DCMS) into the UK's data protection regime, and in particular the proposed relaxation of oversight in relation to automated decision making is somewhat disconcerting: Department for Digital, Culture, Media \& Support (DCMS), Data: A New Direction (10 September 2021). 44. Stephen Thaler, quoted in K Quach (n 35).

45. J Gibson, Owned, An Ethological Jurisprudence of Property: From the Cave to the Commons (Routledge, London 2020), particularly Chapter 10 on incentives and shared interests in intellectual property. 


\section{UN-DISH-COVER THE FISH, OR DISHCOVER THE RIDDLE? ${ }^{46}$}

Having seen it practised several times, that after the Discovery of some new Problem, the Inventor propounds it as a Riddle, to stir up those that are ingenious in the same kind of learning, and make them find sometimes better things then what is propounded: I have thought I might do the same, with a way for raising water, which I think surely to be new, since it is not used in considerable occasions where it might be of great advantage. ${ }^{47}$

(Dr Papin, 'A New Way of Raising Water', 1685)

Returning to the commercial reckoning of the patent system, does DABUS 'devise' a way out of the tyranny of the market towards the provenance and prosociality of the very cultural life of innovation? It is in this complex interaction between property and sociality that the path to personhood may ultimately be paved. To recall the discussion of scientific discovery that introduced this tale, problem formulation and discovery of the law are two different, but not necessarily differently valuable, creative activities. ${ }^{48}$ As a method of attracting enhanced attention on these issues, the DABUS litigation is certainly formulating the problem. It remains to be seen if, and by whom (or by what?), an important discovery in the law will be found.

DABUS, the inventor, propounds it as a riddle. And from that perhaps something ingenious will this way come for patent law.

Johanna Gibson

1 November 2021

46. Lewis Carroll, Through the Looking-Glass, and What Alice Found There (Macmillan and Co, London 1872), Chapter IX, 'Queen Alice', p. 226.

47. Dr Papin, Fellow of the Royal Society 'A New Way of Raising Water' (1685) 15 Philosophical Transactions 1093-4.

48. P Langley et al., Scientific Discovery: Computational Explorations of the Creative Process (The MIT Press, Cambridge, MA 1987) 26. 